\title{
Comunicação transnacional mediada por computador: uma análise discursiva das identidades de futuros professores de inglês no Facebook
}

\author{
Transnational Mediated Communication: a \\ Discursive Analysis of Identities of Future \\ English Teachers on Facebook
}

Bárbara Cristina Gallardo*

Universidade do Estado de Mato Grosso

Cáceres - Mato Grosso - Brasil

RESUMO: Tomando potencialmente inovadoras as oportunidades de Comunicação Mediada por Computador no âmbito da formação de professores de inglês, o objetivo deste artigo é analisar as representaçôes da identidade nacional constituídas em um contexto virtual. Duas estudantes de Letras estabeleceram contato com estrangeiros no Facebook e com eles interagiram em língua inglesa. Utilizou-se a Análise Crítica do Discurso para desvendar a organização linguística e ideológica dos discursos nacionais acionados na transição para o contexto transnacional online. Os resultados sugerem a hibridação de estratégias do discurso de contextos offline com os recursos multimodais dos contextos online. Os sujeitos adotaram estereótipos oriundos de centros geradores das dinâmicas de globalização, tanto em escala regional (sudeste do Brasil) como mundial (os EUA).

PALAVRAS-CHAVE: identidade, ideologia, globalização, comunicação transnacional digital.

ABSTRACT: Taking Computer Mediated Communication opportunities in the education of English teachers as potentially innovative, the aim of this article is to analyze representations of national identity in a virtual context. Two Brazilian students from a Liberal Arts course established contact with adult foreigners on Facebook and interacted with them in English. A Critical Discourse Analysis approach was used to unveil linguistic organization and ideological reproduction of national speeches added in the transition to the online context. The results suggest a hybridization of discourse strategies taken from both offline contexts and online

*barbaracaicara@gmail.com 
contexts with their multimodal resources. The participants used stereotypes in their speeches that come from big cities where globalization dynamics are generated, both at a national scale (southeastern region of Brazil) and worldwide (USA). KEYWORDS: identity, ideology, globalization, transnational mediated communication.

\section{Introdução}

As possibilidades de estar em mais de um lugar ao mesmo tempo, o acesso e a rapidez com que se chega a esses lugares é uma das grandes inovaçôes da internet. Essas possibilidades criam novas formas de se relacionar, estendem o escopo de sociabilidade e abrem possibilidades para novos repertórios e trocas culturais.

Antes disso, as viagens eram os principais meios de se ter acesso mais direto (o contato in loco) às culturas estrangeiras. Já no período da exploração marítima no século XV, povos da Europa circulavam pelos continentes conquistados, levando consigo conhecimento tecnológico militar e científico, ao mesmo tempo em que absorviam o que de melhor encontravam na cultura do outro (DERVIN, 2011). Após a Segunda Guerra Mundial, cresceu o interesse pelo estudo intercultural, quando os Estados Unidos e a antiga União Soviética começaram a buscar controle hegemônico de ideias pelo resto do mundo (KUMARADIVELU, 2006). O modo como as práticas eram combinadas no processo de incorporação da cultura do império norteamericano chamou a atenção de pesquisadores para as semelhanças e diferenças dos povos no modo de ver e participar do mundo (ROGERS; HART, 2002).

O resultado dessas pesquisas mostrou que as transações econômicas afetam a estrutura social global e, consequentemente, as identidades locais em um processo de globalização unilateral. Isto porque, na atualidade, mais da metade de todas as ações e transações ditas globais estão concentradas em Nova Iorque, Londres e Tóquio. Ao mesmo tempo, 47 países em desenvolvimento representam unidos 0,3\% do comércio mundial (SANTOS, 2010).

Do ponto de vista da comunicação, com a intensificação e renovação do processo de globalização, encontros transnacionais podem acontecer de modo mais dinâmico e com maior frequência por meio das novas tecnologias da internet. Através do canal virtual/digital/online, ${ }^{1}$ pessoas comuns podem se

\footnotetext{
${ }^{1}$ Os termos virtual, digital e online referem-se às atividades no computador conectado à internet. Eles têm o mesmo significado neste estudo e serão usados, no decorrer do texto, como sinônimos.
} 
comunicar e trocar experiências sobre o mundo em que vivem de modo dinâmico, sem as limitaçóes geográficas que, no meio físico, determinam as possibilidades de encontro e interação.

A inovação nos modos de comunicação e a ampliação dos encontros nos espaços sociais estabelecidos nas comunidades virtuais me motivaram a tentar compreender de que maneira brasileiros e estrangeiros gerenciam suas identidades sociais/nacionais quando interagem em uma rede social online, onde a ausência do corpo físico desafia os interlocutores a mobilizarem os mais variados recursos linguístico-semióticos para a produção de discursos orientados a ideologias específicas de cada lado dos encontros.

Concentrei-me no estudo do discurso oficial da nação recontextualizado na voz de sujeitos que não representavam o poder ou a mídia (CILLIA; REISIGL; WODAK, 1999), em conversas informais mediadas por computador. Investiguei nesses discursos a construção de identidades apresentadas a amigos virtuais cujos participantes tiveram pouco ou nenhum contato presencial. Assim, foi possível observar a linguagem na produção de discurso online, as estratégias para comunicação, facilitadas ou dificultadas na comunicação mediada e, ao mesmo tempo, compreender o impacto da noção de nação na identidade desses participantes.

Minha experiência como professora de estágio supervisionado de língua inglesa em um Curso de graduação em Licenciatura em Letras influenciou a escolha deste tema. A infraestrutura e localização geográfica da cidade onde o Curso acontece (interior do centro-oeste do Brasil) restringe o contato na língua-alvo com pessoas estrangeiras e com a própria literatura e outras formas de expressão cultural de outros países. Somado à necessidade de formarmos professores de línguas capazes de integrar letramentos digitais, valorizados globalmente, ao cotidiano escolar (BRASIL, 2006), julguei pertinente unir os temas língua estrangeira e tecnologia, com foco nas identidades construídas por estudantes de Letras desta cidade, na interação online com estrangeiros falantes de inglês. Para definir o foco, levei em conta as práticas digitais de interação que já faziam parte do cotidiano dos estudantes. Nesse sentido, Coiro et al. (2008) salientam a necessidade da escola de oportunizar a apropriação efetiva dos novos tipos de letramentos na internet e das novas práticas sociais que vão além das exigidas no meio escolar. Em relação à comunicação transcultural, esses autores destacam a eficácia dos novos letramentos na internet nesse tipo de experiência.

A fim de situar o percurso da compreensão do tema identidade na atualidade, a primeira parte deste artigo faz um mapeamento do modelo de 
construção identitária desde a formação dos Estados-Nação até a era da globalização contemporânea. A segunda parte apresenta as abordagens linguísticas que têm sido usadas no estudo da Comunicação Mediada por Computador, com foco na Análise Crítica do Discurso utilizada na análise dos dados deste estudo. A metodologia que orientou a abordagem dos dados compõe a terceira parte, seguida da análise e das consideraçôes finais.

\section{Identidade e globalização}

O interesse por questôes identitárias teve um aumento significativo na área das ciências humanas desde a segunda metade do século XX, principalmente no que se refere às múltiplas identidades do sujeito. Não por coincidência, nesse mesmo período, o fenômeno da globalização ${ }^{2}$ culminou na exposição e constatação do caráter provisório que rege as práticas das sociedades, ignorado até o início da modernidade (HALL, 2006). Iniciados no século $\mathrm{XVI}^{3}$ e tornandose mais intensos na segunda metade do século XX, ${ }^{4}$ o desenvolvimento científico mundial e as mudanças sociais, econômicas e políticas resultaram na fragmentação do sujeito atomístico e no descentramento dos sujeitos centrados. Desdobramentos da globalização mais recentes, tais como a compressão espaciotemporal (GIDDENS, 1991) e o estabelecimento de uma zona de fronteira ampliada entre o tecnológico e o cultural (BUZATO, 2009), vêm tendo um impacto considerável na identidade cultural dos sujeitos.

\footnotetext{
${ }^{2}$ Kumaradivelu (2006) afirma que a globalização não é um fenômeno novo e que tem significados diferentes, de acordo com a situação mundial de cada época. Este estudo refere-se especificamente aos seus efeitos sociais a partir do século XX.

${ }^{3} \mathrm{O}$ nascimento do protestantismo começa a desencadear mudanças no comportamento social e econômico no século XVI. A fim de ilustrar a formação das culturas de classe, Cuche (2002, p.161) cita o estudo de Weber (1905) acerca da relação entre o pensamento protestante e o desenvolvimento do capitalismo.

${ }^{4}$ Dentre as teorias citadas por Hall (2006), que surgiram nesta época e que podem ter contribuído para o descentramento do sujeito, estão: a descoberta do inconsciente por Freud, a constatação de Lacan sobre a formação do eu a partir do olhar do outro e a teoria de Foucault sobre a submissão do sujeito a um poder disciplinar que tinha como objetivo produzir sujeitos controláveis. Hall (2006) chama a segunda metade do século XX de modernidade tardia. Para esse autor, os avanços do conhecimento humano nesta fase provocaram mudanças radicais nos modos de viver e pensar que sinalizam mais para uma continuidade do projeto de modernidade do que para o início de uma era pós-moderna.
} 
Nessa perspectiva, este fenômeno só escancarou uma característica que, na verdade, vinha se desenhando desde a instauração da modernidade. A noção de unificação e equilíbrio foi enfraquecida pela de um sujeito formado por várias identidades que não necessariamente viviam/vivem em harmonia umas com as outras, nem tampouco precisavam/precisam ser coerentes entre si (HALL, 2006).

Para Bauman (2005), o reconhecimento dessa característica e o estímulo à exposição das identidades, à medida que novas práticas possibilitadas pela globalização se desenvolveram, provocaram mudanças radicais de comportamento, cujas consequências eram/são imprevisíveis. Segundo esse autor, a instabilidade das identidades construídas neste século torna inviável a conclusão definitiva sobre nós mesmos e sobre os outros. A modernidade líquida proposta por Bauman (2005) para denominar o período atual da história está relacionada, entre outros fatores, à constante negociação de nossas múltiplas identidades na nova dinâmica do ser e viver em sociedade. A diferença em relação a épocas anteriores está no caráter provisório das relações, assim como na rapidez com que mudanças de comportamento e sentimento acontecem.

Com o foco no estreitamento de relações entre amigos representadas na forma de redes egocêntricas, a rede social Facebook, por exemplo, promove a postagem de diversos assuntos pessoais ou não, que podem ser visualizadas e que incentivam os amigos a comentar sobre o que foi postado e sobre os comentários dos outros sobre o mesmo assunto, criando um mecanismo poderoso de contextualização social da informação semântica rastreada pelo sistema computacional.

Nesse sentido, graças à internet surgiram características próprias da comunicação na sociedade em rede, antes determinadas somente pelo contexto e relações interpessoais do espaço físico. Por exemplo, a compreensão de privacidade como um direito e as referências e relações comunitárias locais perderam boa parte de sua força na constituição das dinâmicas identitárias, que agora se apoiam em práticas de participação online e publicização da vida privada.

Outra característica dessa nova relação de tempo-espaço é a abertura e popularização da internet que veio acompanhada de uma homogeneização de atitudes e gostos generalizada, incentivada pelo consumismo excessivo característico da etapa atual do capitalismo globalizado. ${ }^{5}$ Para Hall (2006), essa

\footnotetext{
${ }^{5}$ Alguns autores, dentre eles, García Canclini (2005), ressaltam a forma desigual com que a globalização chega a países que ainda não vivem a pós-modernidade (ou modernidade tardia) em termos sociais, culturais e educacionais.
} 
difusão do consumismo (mesmo que na forma de um sonho) no meio virtual ajudou a construir um tipo de identidade compartilhada que, ao mesmo tempo em que favoreceu o surgimento de uma homogeneização cultural, incentivou manifestações contrárias à homogeneização.

Assim como o contexto sociocultural mais amplo, as relações interpessoais influenciam sobremaneira a construção de identidades, tanto no espaço virtual quanto fora dele, pois é o contexto relacional que determina a afirmação ou repressão de determinada identidade (CUCHE, 2002). Neste artigo, por exemplo, acredito que as construçóes identitárias, verificadas nos dados e que aconteceram mais frequentemente no contato com estrangeiros de origem norteamericana, foram pautadas em subjetividades encenadas, absorvidas na fronteira entre os espaços on e offline. A autorrepresentação neste caso foi construída por partes de todos os lugares e discursos que alcançaram as participantes brasileiras em situações reais ou veiculadas pela mídia, para então serem vividas, pelo menos no imaginário, ou ainda, na experiência digital.

Esta é uma situação desafiadora para os sujeitos, uma vez que a multiplicidade de vozes e de modos de ver o mundo em uma só cultura já requisita uma gama de diferentes identidades. A concepção do espaço virtual sem as fronteiras geográficas como espaço alternativo, onde os usuários estão relativamente mais livres de alguns de seus confinamentos sociais offline, aciona a possibilidade de expor a si próprio e a sua cultura obedecendo, por gosto, escolha ou coerção, a outras regras sociais. Essa prática influi, direta ou indiretamente, na performance das identidades sociais que atuam em outros espaços de circulação, uma vez que as identidades são sempre relacionais. Assim, com o advento da internet e das Tecnologias de Informação e Comunicação (TICs), o acesso a outras visões e práticas sociais e outras subjetividades expressas em outros sistemas linguísticos tornou-se mais abrangente, influenciando a maneira como os sujeitos constroem suas identidades tendo em vista outras regras e referenciais.

Redes Sociais Virtuais como o Facebook são fenômenos da cultura de compartilhamento e exposição porque incentivam a participação por meio da distribuição de informação pública e privada de conteúdo. Por meio das práticas nelas disponibilizadas, as identidades são remediadas em contextos de Comunicação Mediada por Computador, porque perdem as pistas conceituais disponíveis no meio offline, e passam a ser veiculadas por meio dos recursos linguísticos próprios dos contextos virtuais. O Facebook, especificamente, incentiva a circulação de informação, a manifestação criativa, crítica, etc. dos usuários, próprias para atuar em seu contexto. Outros contextos virtuais 
oferecem outras possibilidades de participação e, assim, outros modos de construção identitária. Isto significa que os recursos e as restrições de cada espaço no meio virtual moldam a participação do usuário.

A seção 2 a seguir apresenta alguns dos recursos linguísticos-discursivos usados na Comunicação Mediada por Computador que se constituem a partir das variáveis técnicas e situacionais disponíveis nos contextos virtuais.

\section{Linguagem da Comunicação Mediada por Computador}

Na pesquisa, a produção de texto escrito característica da Comunicação Mediada por Computador (doravante CMC) facilita a armazenagem e análise da linguagem em contextos online de interação. As formas de comunicação, por exemplo, em fóruns, grupos de discussão, e-mails, etc. seguem variedades linguísticas dependentes do contexto cultural de uso, próprias de cada espaço. Como nesses contextos a informação é limitada ao texto digitado, interessa aos pesquisadores saber como são veiculados os significados que no meio offline contam com as pistas visuais (gestos, olhar, etc.) (HERRING, 2004a). A representação textual das ações e das expressões faciais nos contextos da CMC faz da linguagem o recurso principal de criação da realidade neste tipo de comunicação, o que torna relevante uma abordagem discursiva do conteúdo produzido nesses contextos (HERRING, 2001).

Os primeiros estudos na CMC observavam as construçóes linguísticas com foco na estrutura da língua, ou seja, nas escolhas lexicais, formação de novas palavras, estrutura das sentenças, etc. À medida que suas funções foram se ampliando (por exemplo, reclamar, votar, compartilhar conteúdo) e suas práticas se tornando cotidianas, a linguagem produzida na CMC passou a ser estudada sob pontos de vista discursivos, com análises que investigam relações de poder, manifestações de gênero, de identidade, dentre outras.

Bauer (2000) dividiu os estudos que observou na CMC em sintáticos e semânticos. Os estudos sintáticos concentram-se na estrutura da produção de linguagem (ortografia, sintaxe, morfologia) e os semânticos dedicam-se à relação entre a organização interna das sentenças (conflito, negociação) e os aspectos externos (contexto social), ou seja, a produção de discurso.

A partir da divisão sugerida por Bauer, Herring (2004b) classificou esses dois tipos de abordagens sob o termo abrangente Análise do Discurso Mediado por Computador. ${ }^{6}$ No entanto, devido às especificidades dos métodos

${ }^{6}$ Em inglês, Computer Mediated Discourse Analysis (CMDA). 
qualitativos que cada teoria exigia, Herring (2004b) produziu um quadro no qual selecionou, dentre as diversas possibilidades de análise linguísticodiscursiva da CMC, cinco paradigmas de análise do discurso e seus respectivos procedimentos de investigação, os quais reproduzo na tabela 1 , a seguir:

\section{TABELA 1}

Paradigmas de cinco teorias/métodos de Análises do Discurso

\begin{tabular}{|l|l|l|l|}
\hline & Temas & Fenômeno & Procedimentos \\
\hline $\begin{array}{l}\text { Análise de texto (cf. } \\
\text { Longacre, 1996). }\end{array}$ & $\begin{array}{l}\text { Classificação. } \\
\text { Descrição, "textura" } \\
\text { dos textos. }\end{array}$ & $\begin{array}{l}\text { Gêneros, organização } \\
\text { esquemática, referência, } \\
\text { saliência, coesão, etc. }\end{array}$ & $\begin{array}{l}\text { Identificação de } \\
\text { regularidades estruturais } \\
\text { dentro e entre os textos. }\end{array}$ \\
\hline $\begin{array}{l}\text { Análise da } \\
\text { conversação } \\
\text { (cf. Psathas, 1995). }\end{array}$ & $\begin{array}{l}\text { Interação como uma } \\
\text { realização de nego- } \\
\text { ciação conjunta. }\end{array}$ & $\begin{array}{l}\text { Tomada de turno, } \\
\text { sequências, desenvolvi- } \\
\text { mento de tópico, etc. }\end{array}$ & $\begin{array}{l}\text { Análise detalhada dos } \\
\text { mecanismos de interação. }\end{array}$ \\
\hline $\begin{array}{l}\text { Pragmática (cf. } \\
\text { Levinson, 1983). }\end{array}$ & $\begin{array}{l}\text { Língua como ativi- } \\
\text { dade - "fazer coisas } \\
\text { com as palavras". }\end{array}$ & $\begin{array}{l}\text { Atos da fala, relevância, } \\
\text { polidez, etc. }\end{array}$ & $\begin{array}{l}\text { Interpretação das intençóes } \\
\text { do falante das evidências } \\
\text { do discurso. }\end{array}$ \\
\hline $\begin{array}{l}\text { Sociolinguística } \\
\text { interacional (cf. } \\
\text { Gumperz, 1982; } \\
\text { Tannen, 1993). }\end{array}$ & $\begin{array}{l}\text { Papel da cultura } \\
\text { no modelamento } \\
\text { e interpretação da } \\
\text { interação. }\end{array}$ & $\begin{array}{l}\text { Gêneros verbais, estilos } \\
\text { do discurso, mal- } \\
\text { entendido, framing, etc. }\end{array}$ & $\begin{array}{l}\text { Análise dos significados } \\
\text { socioculturais detectados } \\
\text { na interação. }\end{array}$ \\
\hline $\begin{array}{l}\text { Análise Crítica } \\
\text { do Discurso (cf. } \\
\text { Fairclough, 1992). }\end{array}$ & $\begin{array}{l}\text { Discurso como lugar } \\
\text { em que o poder } \\
\text { e o significado } \\
\text { são contestados. }\end{array}$ & $\begin{array}{l}\text { Transitividade, pressupo- } \\
\text { sição, intertextualidade, } \\
\text { controle conversacional, } \\
\text { etc. }\end{array}$ & $\begin{array}{l}\text { Interpretação do } \\
\text { significado e estrutura } \\
\text { em relação à ideologia, } \\
\text { dinâmica de poder. }\end{array}$ \\
\hline
\end{tabular}

Fonte: HERRING, 2004b, p.359.

As abordagens discursivas da CMC têm um caráter mais interpretativo e subjetivo do que as abordagens estruturais, com a vantagem de poderem também lançar mão de uma análise estrutural (incidência dos emoticons, características gramaticais particulares, atos da fala etc.) para verificar hipóteses.

A análise do discurso mediado por computador parte de três premissas: os discursos exibem padrões recorrentes produzidos de forma consciente ou não; o discurso envolve escolhas do falante que não são somente linguísticas, mas refletem fatores cognitivos e sociais; o discurso pode ser moldado por características tecnológicas dos sistemas de CMC. O que difere as duas primeiras da investigação em contextos offline são as variáveis técnicas e situacionais do contexto virtual que moldam as condições de produção (HERRING, 2004a).

As variáveis técnicas incluem a perda de feedback instantâneo da mensagem captado no contexto offline por meio das pistas audiovisuais 
(HERRING, 1999); as limitações de espaço e de número de caracteres possíveis de serem digitados e enviados de uma só vez; a sincronicidade, por exemplo, a sobreposição de mensagens nas trocas de turno em uma comunicação síncrona ou, na comunicação assíncrona, a irrelevância que adquirem as mensagens dependendo do momento em que são lidas; os canais de comunicação (visual, textual, de áudio, etc.), cada um com recursos e restrições próprias; o anonimato dos interlocutores, dentre outras (HERRING, 2004b).

Entre as variáveis situacionais estão as características do contexto (formal, informal, acadêmico, etc.), o tópico tratado, o objetivo da mensagem eseu status (público ou privado), as normas (de participação de uso da língua, de comportamento, etc.), a experiência prévia do participante, a estrutura de participação (se a mensagem é trocada entre duas ou mais pessoas) (BAYM, 1996), etc.

Essas variáveis foram observadas em contextos da CMC entre pessoas de mesma nacionalidade. No caso deste estudo, interessava-me investigar a construção de identidades no discurso na comunicação transnacional, ou seja, entre pessoas de diferentes nacionalidades. Neste caso, a Sociolinguística Interacional e a Análise Crítica do Discurso (na Tabela 1) pareceram ser as mais pertinentes, uma vez que relacionam as variedades discutidas sem perder de vista os aspectos socioculturais e ideológicos do discurso na relação entre texto e contexto social. Optei pelo uso da metodologia da Análise Crítica do Discurso (doravante ACD) de Fairclough (1992, 1995, 2003) para a análise dos dados, primeiro por ter experiência com este procedimento de análise ${ }^{7} \mathrm{e}$ também com o intuito de trazer uma contribuição para a pesquisa da ACD no espaço virtual no Brasil, já que ainda não há uma variedade de estudos que unam esse enfoque e contexto (virtual) no país. Ademais, acredito que esta teoria oferece suporte para salientar a linguagem da CMC com destaque para as ideologias nacionais e globais dos contextos on e offline de produção, que influenciam a construção virtual do sujeito. A seguir, apresento brevemente as principais características da ACD.

\subsection{A Teoria da ACD aplicada ao Discurso na CMC}

Caracterizada pela não neutralidade, a ligação entre texto e contexto proposta pela ACD é usada no entrelace dos fatos, inseridos nas práticas social e discursiva das quais ideologia e poder são parte intrínseca. A ACD é considerada uma teoria e um método de análise (MEURER, 2005) com foco na relação dialética entre linguagem e sociedade. Ela surgiu a partir de estudos 
de um grupo de pesquisadores ligados à linguística crítica, ${ }^{8}$ o qual propôs que as visões de mundo particulares incorporadas à língua (tese da hipótese SapirWhorf) têm conexão direta com as ideologias presentes no contexto social dos falantes.

A noção de relação dialética entre o discurso e as estruturas sociais é incorporadaà ACD a partir de teorias sociológicas. Já os efeitos constitutivos do discurso seguem os preceitos de Foucault (1972), que percebeu que os indivíduos criam realidades sociais e conhecimento a partir das estruturas de poder aos quais estão submetidos (MEURER, 2005). Apesar dos diferentes enfoques dados ao discurso nos trabalhos de Foucault (1972) ${ }^{9}$ e na ACD, Foucault trouxe duas importantes contribuiçôes para a formulação desta teoria: a visão constitutiva do discurso em relação direta com a formação da sociedade, das relaçôes sociais e dos sujeitos; a interdependência das práticas discursivas em textos prévios, capazes de mudar o curso de textos posteriores ${ }^{10}$ (FAIRCLOUGH, 2003).

A união de uma teoria social e uma teoria linguística busca trazer à tona os modelos ideológicos que permeiam as construções discursivas e as relações que estabelecem. Fairclough (1992) dedica-se ao estudo do discurso na perspectiva de que nele acontece a luta entre a manutenção e a mudança da realidade dada. A intertextualidade é um conceito fundamental na abordagem deste fenômeno, porque embora criativa, a organização intertextual, tanto do

\footnotetext{
${ }^{7}$ Principalmente em estudos desenvolvidos para a elaboração da minha dissertação de mestrado, no Curso de Pós-graduação em inglês da Universidade Federal de Santa Catarina, reconhecido nacionalmente como um dos polos de pesquisa em ACD no Brasil.

${ }^{8}$ Este termo (em inglês, critical linguistics) foi usado pela primeira vez por Fowler, Hodge, Kress e Trew em um dos capítulos do livro Language and Control. O objetivo da linguística crítica era o de interpretar os textos criticamente, relacionando as estruturas linguística e social (FOWLER et al., 1979).

${ }^{9} \mathrm{O}$ trabalho de Foucault (1972) é voltado para uma abordagem abstrata do discurso científico e para as relações entre o saber e o poder. Em comparação à ACD, Fairclough (1992) ressalta o seu foco em todo tipo de discurso - político, médico, da mídia, da sala de aula, etc. - porém, orientado por uma análise linguística, fundamental, segundo este autor, para a compreensão dos efeitos sociais do discurso (FAIRCLOUGH, 2003).

${ }^{10}$ Esta característica - a inclusão de textos prévios em novos textos - foi denominada intertextualidade, por Julia Kristeva no final dos anos 60, em referência aos trabalhos de Bakhtin sobre o discurso literário (FIORIN, 2006).
} 
discurso de manutenção quanto o de mudança, é ditada por instâncias de poder. Bakhtin (1986) chamou a atenção para a propriedade dialógica da linguagem, ${ }^{11}$ ressaltando que o enunciado é sempre formado por duas vozes que ocupam posições distintas. Os textos (orais e escritos) funcionam como correntes em conexão com textos anteriores que, inconscientemente ou não, respondem ou antecipam o que foi dito e/ou escrito antes. Os conceitos de intertextualidade e dialogismo são importantes na $\mathrm{ACD}$, pois, como os textos tomam forma e se estabelecem nas relações sociais através do discurso, são também responsáveis pela construção de identidades e pelo contato com sistemas de conhecimento e crença (FAIRCLOUGH, 1992).

Por exemplo, a globalização contemporânea, as novas noçōes de tempo/ espaço e o advento das TICs são modos de representação (discursos) que provocaram mudanças nos modos de gerar conhecimento e informação, nos valores e nas práticas e, portanto, influenciaram a estruturação dos gêneros e estilos (FAIRCLOUGH, 2003). Os gêneros, por exemplo, embora estáveis, têm sofrido transformações relacionadas à hibridação de linguagem (formal e informal), realocação de conteúdo (de artigos para entrevistas) e de contextos (de livros para sites, etc.), moldadas segundo as regras do novo capitalismo. ${ }^{12}$ A globalização impulsiona a disseminação dessas tendências que interferem na dinâmica das práticas sociais no mundo todo e, consequentemente, nos discursos e estilos em uma perspectiva local e global (FAIRCLOUGH, 2006).

Aplicando-se este modelo ao estudo da comunicação virtual, partese do princípio de que a produção, consumo e distribuição de informação e conhecimento são feitos a partir de um mapa de estratégias cognitivas aprendidos nos meios sociais on e offline, ou seja, no contato com os gêneros disponíveis. Por exemplo, o domínio do meio digital (figuras, emoticons, etc.), o conhecimento de diferentes gêneros neste contexto (bate-papo, mensagem privada) e a compreensão da relação de interesses de instituições sociais (sites, empresas, governo, etc.) nas mensagens da mídia influenciam a negociação e produção de significado (LUKE, 2000).

\footnotetext{
${ }^{11} \mathrm{Na}$ descrição do dialogismo no discurso (principalmente no discurso do romance), Bakhtin usa também os termos discurso citado, polifonia, plurilinguismo, hibridismo e intercalação (ROJO, 2005, p.188).

12 Fairclough (2003) chama esta nova era de novo capitalismo em referência à continuidade do modelo capitalista de controle não só da área econômica, mas da vida social.
} 
Um enfoque linguístico e social na análise dos discursos que internalizam as práticas da nova era pretende revelar "como as pessoas habitam simultaneamente os espaços-tempos diferentes (por exemplo, espaços-tempos locais e globais) e se movimentam entre eles no cotidiano"13 (FAIRCLOUGH, 2003, p. 16). Nesse sentido, a análise da produção textual que propõe a ACD de Fairclough funciona não somente como uma descrição da gramática do texto, mas como uma ponte entre os significados e questôes sociais que permeiam os discursos construídos nesses movimentos.

A análise sistemática do texto, representado pela "língua falada ou escrita produzida em um evento discursivo" 14 (FAIRCLOUGH, 1993, p. 138), inclui som e imagens (os vídeos produzidos para compor as páginas de rede social, por exemplo) que também fazem parte dos recursos semióticos (linguagem corporal, vestimenta) remediados no meio virtual e usados na construção do discurso online.

Como referência à construção textual do discurso, Fairclough (2003) compartilha a visão multifuncional da linguagem da Linguística SistêmicoFuncional proposta por Halliday $(1985,1994)$, preferindo chamar de significados ao invés de funçôes da linguagem a construção que o sujeito faz da realidade. $\mathrm{Na}$ abordagem de Halliday, a língua constrói três significados simultaneamente, representados por três metafunções: a ideacional (representa a realidade); a interpessoal (cria relações entre os interlocutores em eventos sociais); e a textual (organiza coesivamente a mensagem e a conecta ao contexto situacional). Fairclough(2003) estabelece, comotiposdesignificadosexpressosnalinguagem, a Representação, a Ação e a Identificação. Em comparação à denominação dada por Halliday, a Representação corresponde à metafunção ideacional; a Ação e a Identificação correspondem à metafunção interpessoal. Fairclough não considera a função textual como separada das outras, mas incorporada à Ação, uma vez que compreende o texto não somente como um meio para se criar relaçóes sociais (criar significados), mas também como o meio que possibilita a (inter)ação dos sujeitos em eventos sociais. A inter-relação estabelecida entre as práticas abstratas (social e discursiva) e concreta (texto) justifica-se na abordagem crítica de Fairclough $(1995,2003)$ por ser o texto não um fim, mas um meio que aponta para questões sociais complexas. Segundo esse autor, "não é possível compreender

13 “(...) how people simultaneously inhabit different 'space-times' (e.g. 'global' and 'local' space times) and routinely move between them."

14 “(...) the written or spoken language produced in a discursive event". 
os efeitos sociais do discurso sem observar o que acontece quando as pessoas falam ou escrevem"15 (p.3).

Na perspectiva de Halliday, a língua é a materialização da realidade. Neste caso, para as duas funções da linguagem - expressar sentido da experiência humana e proporcionar a interação - a gramática age como "interface" com o que acontece fora da língua, ou seja, "com os acontecimentos e condições do mundo e com os processos sociais aos quais nos engajamos" 16 (HALLIDAY; MATTHIESSEN, 2004, p.24). As escolhas vão sempre incluir certos aspectos e excluir outros graças às possibilidades dadas pela linguagem para a exteriorização do pensamento, dentre elas o som das palavras, a entonação (na fala), o ponto de exclamação (na escrita), as polaridades positiva (eu quero água) e negativa (eu não quero água), a modalização, etc.

Dentre as três metafunções da linguagem observadas por Halliday $(1985,1994)$, me atenho, neste artigo, à metafunção interpessoal pelo seu enfoque nas construções identitárias e nas relações sociais. Destaco, especificamente neste recorte, as polaridades positiva e negativa usadas pelas participantes brasileiras para salientar sua aproximação/distanciamento com a nação brasileira e/ou com outras nações.

\section{Metodologia}

A metodologia utilizada é considerada um estudo de caso do tipo descritivo, o qual permite o uso de métodos qualitativos e quantitativos, e o envolvimento do pesquisador na investigação (COUTINHO; CHAVES, 2002). O estudo tem caráter interpretativista e exploratório e foi constituído principalmente por meio de análise qualitativa. Uma análise quantitativa destacou a frequência de declarações afirmativas e negativas na separação do corpus de brasileiras e estrangeiros. Os resultados desta etapa auxiliaram na formulação dos resultados da análise qualitativa.

Como parte do levantamento de dados do contexto físico, utilizei métodos etnográficos, tais como a observação não participante, a coleta de textos e os instrumentos, notas de campo e conversas informais. Estes dados

\footnotetext{
15 “(...) no real understanding of the social effects is possible without looking closely at what happens when people talk or write". (p.03)

16 " (...) with the happenings and conditions of the world, and with the social processes we engage in”. (p.24)
} 
serviram para complementar minha própria vivência no contexto offline. Para o contexto online, examinei o perfil das participantes brasileiras no Facebook e os mecanismos disponíveis neste site. Por meio de um questionário e duas entrevistas, verifiquei também a experiência das brasileiras nesta rede social e em contextos online desse tipo. Adicionalmente, as participantes me deram acesso aos seus perfis, o que me permitiu observar o modo como elas vinham atuando ao longo do estudo.

Uma vez que os usuários estabelecem formas específicas para comunicação online que são diferentes da comunicação face a face (MARKHAM, 2004), a internet foi, neste estudo, concebida como um produto e um espaço cultural. Para isso, escolhi uma situação na qual as interações offline não seriam possíveis para as participantes desta experiência, ou seja, interações transnacionais.

Participaram do estudo uma estudante recém-formada em um Curso de Letras e uma estudante matriculada no primeiro semestre do mesmo Curso. Ambas estavam em um nível intermediário da língua inglesa. Elas foram orientadas a fazer amizade/interagir com estrangeiros pelo Facebook e se corresponder com eles por seis meses. O critério para a escolha dos interlocutores estrangeiros era o de que falassem inglês como primeira ou segunda língua. A opção pela análise das interações na língua estrangeira foi feita com o objetivo de verificar a construção de identidades dessas brasileiras na interação com estrangeiros no meio virtual.

Os dados coletados consistiram de interações síncronas e assíncronas de mensagens privadas e sessões de bate-papo dentro do site Facebook. Não foram dadas instruções específicas às participantes sobre como interagir ou de que assunto abordar, a não ser de que se tratava de uma experiência de comunicação transnacional. Essa estratégia foi usada a fim de analisar trocas o mais espontâneas possível. As participantes ficaram livres para interagir na hora em que quisessem e sem especificação de volume de interações, a não ser a instrução de que trocassem ao menos uma mensagem a cada duas semanas. As informaçôes sobre a data das interações, o nome e as informações pessoais de todos os participantes e dos amigos que mencionaram foram retiradas das transcrições. Os nomes que apareceram foram alterados para nomes fictícios. Não foram dadas especificações aos estrangeiros já que eles foram escolhidos aleatoriamente pelas estudantes brasileiras. Os estrangeiros só ficaram sabendo que as interações seriam analisadas ao final de seis meses, quando as brasileiras pediram formalmente seu consentimento para a utilização dos registros de suas conversas na pesquisa. 


\section{Análise de Dados}

Nesta seção, apresento a análise de parte dos dados observados nas interações presentes nas páginas do Facebook das participantes brasileiras Bruna e Nara. ${ }^{17}$ Adicionalmente, traço um breve histórico dessas participantes a fim de situar a formação identitária de cada uma.

\section{Bruna: "I have a Visa, but he doesn't."}

Bruna tinha 22 anos no período da pesquisa, era recém-formada e trabalhava como professora de inglês em uma escola de idiomas. Ela, que aprendeu inglês em uma escola de idiomas, definiu-se como uma pessoa apaixonada pela língua inglesa e pela cultura norte-americana. Por esse motivo, tentava estar sempre em contato com a língua-alvo, assistindo a séries de TV, filmes e constantemente interagindo, através do Facebook, com os amigos que fez em 2009 em uma visita de 10 dias à família hospedeira de sua irmã, que trabalhou como babá no estado da Carolina do Norte-EUA, no ano de 2004.

Esta participante era solteira e nascida em uma cidade do sudeste do Brasil. Ela mudou-se aos 4 anos de idade para a cidade da pesquisa, devido a melhores oportunidades de trabalho para seu pai, que era topógrafo.

O discurso de Bruna na construção de sua identidade para os estrangeiros, todos norte-americanos e já conhecidos pessoalmente, foi marcado por estratégias que tiveram o intuito de aproximá-la da cultura norteamericana. Para atingir seu objetivo, a brasileira: i) distanciou-se das referências da cultura brasileira; ii) incorporou o domínio cultural do outro país como algo natural. Sua posição social na sociedade brasileira no que diz respeito à classe social, educação e acesso a recursos permitiu tal construção. Cuche (2002) usa o termo identificação ao invés de identidade para descrever casos em que a construção de identidades gira em torno da identificação do falante com as características e modos de vida de seu interlocutor. A análise da interação entre Bruna e seus interlocutores apontou essa característica na sua construção identitária.

Segundo Wodak (1996, p.17), “(...) o discurso como prática social implica em uma relação dialética entre um evento discursivo particular e uma situação, instituição e estrutura social que o delimita. O evento discursivo é

${ }^{17}$ Neste artigo, os nomes das participantes brasileiras e dos estrangeiros foram substituídos por nomes fictícios. 
modelado por esses aspectos, mas também os modela" ${ }^{18}$ Por exemplo, o fato de dominar a língua inglesa deu confiança a Bruna, no sentido de se diferenciar dos brasileiros que não dominam esta língua. Essa confiança está atrelada às situaçôes em algumas regiões do Brasil, nas quais ser professor de inglês pode ser sinônimo de prestígio (COX; ASSIS PETERSON, 1999). Este é o caso da cidade onde residiam as participantes deste estudo.

No excerto 1, por exemplo, Bruna fala sobre uma possibilidade de emprego e das dificuldades enfrentadas em sua profissão:

\section{Excerto 1}

(...)

Linha 1: Bruna (B): Gil and I will take a test to teach English at the University the pay is well

L 3: $\quad$ Rita: (...) Good luck. I know you'll do well.

(...)

L 4: B: I hope I do fine / and Gil too / because we like the same thing, we have the same job/ english language is our passion ${ }^{19} /$ and we have to make money with this.... LOL

$L 7: \quad R$ : it is good to make money doing something you love.

L 8: $\quad$ B: Yeah....it is/ but sometimes it's hard/ people here in Brasil do not like to learn english / they are lazy/ LOL

L 10: R: lol

L 11: B: they say the language is difficult and just it/ they do nothing to improvel they cross their arms and wait for the teacher...

L 13: $\quad R$ : it is hard sometimes / Fred says hi

L 14: B: teachers have to do everything / Hi/ Hi to Him too/;)/ they say they won't need the language.....

O excerto 1 denota a distância que Bruna quer tomar dos brasileiros. A exaltação da língua-alvo feita para a amiga na linha 5 (english language is our passion: a língua inglesa é nossa paixão) sugere o desejo de filiação ao grupo estrangeiro em oposição ao grupo brasileiro. $\mathrm{O}$ fato de se comunicar com uma norte-americana guia a construção do discurso de Bruna, uma vez que as identidades se constroem nos discursos a partir da relação que se tem com

18 “(...) discourse as social practice implies a dialectical relationship between a particular social event and the situation, institution and social structure that frame it: the discursive event is shaped by them, but also shapes them."

${ }^{19}$ As ênfases nos excertos apresentados neste estudo foram adicionadas por mim. 
outras (CUCHE, 2002) e das relações de poder entre eles (FAIRCLOUGH, 2001). Estas são dadas dentro das condições sócio-históricas, na construção da realidade social dos participantes da interação (MOITA LOPES, 2002).

$\mathrm{Na}$ linha 9, Bruna distancia-se do adjetivo lazy (preguiçoso) através do uso do pronome excludente da terceira pessoa do plural - they (eles). Essa declaração indica um movimento desta participante no sentido de construirse como uma não brasileira, uma vez que os brasileiros são preguiçosos, mas ela não é.

No que se refere à estrangeira $R$, a mudança de assunto na linha 13 (Fred says hi: o Fred tá dizendo 'oi') pode ser interpretada como um sinal de que ela não estava se sentindo confortável em ouvir as reclamações da Bruna, ou ainda, de que ela estava sentindo vergonha alheia da posição que se colocou a brasileira.

Os enunciados 1 a 6 do excerto 2 a seguir são exemplos de construção de imagem positiva de Bruna e negativa dos brasileiros. Esses enunciados foram retirados de interações com os três estrangeiros com quem esta brasileira se correspondeu no período do estudo. A posição de professora de inglês de Bruna, sua opinião e obrigações que a contrastam do resto do grupo de brasileiros foram separadas nos exemplos a seguir. Neles, Bruna exalta o fato de saber falar inglês (linhas 1 e 2), registra o seu esforço/ação em oposição à inércia dos outros (linhas 3 e 4), seu desejo de mudança (linha 5) e sua situação com o consulado estrangeiro (L 6) (que é contrária à situação do namorado). No contexto das interaçôes, as declarações de Bruna soam como uma crítica aos estudantes e ao namorado dela, pelo fato de que não se interessam pelo aprendizado da língua inglesa:

Excerto 2 - Declarações de Bruna (sobre ela mesma):

L1 - English is our passion [dela e da irmã]

L2 - (...) teachers have to do everything (...)

L3 - I teach him English (...) [ him = o namorado $]$

L4 - I teach them English (...) [them = os alunos]

L5 - I pray for it... always pray... [it = para que os alunos queiram aprendam inglês]

L 6 - I have the Visa (but He doesn't) [He = o namorado]

No excerto 2, Bruna usa a polaridade positiva para enfatizar sua proximidade com a língua. Nessa demonstração, a brasileira parece tomar para si a responsabilidade pelo aprendizado dos alunos e do namorado e a conceber como natural o fato de as pessoas terem que gostar de aprender inglês. As declarações da brasileira fortalecem seus sentimentos e postura positivos em relação ao inglês. Em 
contrapartida, Bruna usa a polaridade negativa para expressar a condição diferente dos outros brasileiros, neste caso, seus alunos e namorado:

Excerto 3 - Declarações de Bruna (sobre os outros):

L 7 - My students do not do homeworks (...)

L 8 - They do nothing to improve (....) [they = os alunos $]$

L 9 - They don't like English [they = os alunos]

$\mathrm{L} 10-\mathrm{He}$ does not want to learn English $[\mathrm{He}=\mathrm{o}$ namorado]

L 11 - He does not want to speak English $[\mathrm{He}=o$ namorado]

L 12 - If he does not get the Visa, we can't go to Miami [he = o namorado]

O contraste entre as declarações afirmativas dos sujeitos Bruna, we (ela e a irmã) e $I$ e as declarações negativas (excerto 3) atribuídas aos sujeitos they [os alunos], he [o namorado] auxiliam na construção de identidades distantes entre esta participante e os brasileiros.

Outro exemplo desse contraste pode ser verificado nas declarações do excerto 4 a seguir. Nelas, Bruna faz ofertas distintas em relação ao tema "Carnaval" oferecido na linha 13: uma em relação aos brasileiros (linha 14) e a outra sobre ela própria (linhas 15 e 16). A oferta das ações dos brasileiros tem o objetivo de explicar o motivo pelo qual ela não gosta dessa festa:

\section{Excerto 4}

L 13 - Next week is Carnival... I don't like this holiday

L 14 - People drink and dance a lot...

L 15 - I'm not this way...

L 16 - I prefer to stay home.

Novamente o contraste de opiniōes e ideias vem identificado pelas polaridades opostas, nas declaraçôes "I don't like..." e "I’m not"("eu não gosto..." e "eu não sou...") Nesses enunciados, é Bruna quem nega a condição que, segundo ela, faz parte da natureza dos brasileiros, ou seja, "drink and dance a lot" (beber e dançar muito) versus "I prefer to stay home" (eu prefiro ficar em casa), declaração que completa a negativa anterior "Im not this way"("eu não sou assim"). "Assim" neste caso, quer dizer "como eles". Essa característica foi uma constante na construção identitária de Bruna, na interação com seus amigos estrangeiros.

Ao contrário de Bruna, a participante Nara, construiu uma imagem superpositiva do Brasil e dos brasileiros, conforme mostram os dados a seguir.

Nara: "We eat rice and beans every day in all regions." 
Nara tinha 19 anos e cursava o oitavo semestre de letras na época da coleta de dados. Ela era casada e morava em uma cidade que fica a $150 \mathrm{~km}$ da cidade onde a pesquisa foi realizada. Por esse motivo, passava a semana na casa de sua mãe, na cidade onde nasceu e onde morava antes de se casar e ia para sua casa nos fins de semana.

Assim como Bruna, Nara aprendeu inglês em uma escola de idiomas e tinha acesso à internet em casa. Ela nasceu na capital do estado onde a pesquisa foi realizada e mudou-se para o interior quando tinha 6 anos, devido às melhores oportunidades para seu pai desempenhar a função de eletricista. Nara gostava de usar a internet para ler as notícias, estudar e manter contato com seu marido e amigos.

Esta brasileira nunca tinha tido contato com estrangeiros que falavam a língua inglesa. Como estratégia para fazer amigos, ela deu e pediu informaçóes nas solicitaçóes de amizade que enviou, da seguinte forma:

I'm Brazilian, I'm looking for international friends, I'd be happy if you accepted me. What do you do on weekends in your city for having fun? Here in Brazil we usually go to the mall, go to the club and bowling. ${ }^{20}$

As mensagens foram mandadas de forma aleatória aos usuários do Facebook que Nara buscava, digitando nomes e sobrenomes no espaço de busca (por exemplo, Rose, Mary, Johnson, etc.). A única restrição, segundo relatado em entrevista, era em relação ao sexo das pessoas contatadas, uma vez que seu marido a "preveniu do perigo" de se corresponder com homens pela internet. Mesmo assim, a coleta de dados indicou a troca de mensagens entre Nara e pessoas do sexo masculino.

A identidade nacional de Nara foi realçada nas interações com os estrangeiros com as quais fez amizade por meio de declaraçôes afirmativas e adjetivos positivos. Três estratégias principais foram identificadas para construir sua identidade: $i$ ) supervalorizar as coisas e lugares do Brasil; $i$ i) pontuar ações, preferências e características valorizadas globalmente como naturais no Brasil e dos brasileiros; iii) construir uma representação homogeneizada do Brasil e dos brasileiros a partir de estereótipos.

20 "Eu sou brasileira e estou procurando amigos internacionais, eu ficaria feliz se você me aceitasse. O que você faz para se divertir no final de semana? Aqui no Brasil, nós geralmente vamos ao cinema, ao clube e jogar boliche." 
A não ser para apresentar-se como uma universitária - I'm an undergraduate student - (eu sou uma estudante universitária), e falar sobre uma de suas atividades especificamente-Istudy English - (eu estudo inglês), esta participante usou o pronome pessoal plural inclusivo we (nós) para descrever gostos e atividades rotineiras dos brasileiros. A frase Here in Brasil, we [+ verb]... (Aqui no Brasil, nós+verbo), que sugere a homogeneidade nas atividades do povo brasileiro, foi recorrente em suas declarações, que foram completadas com aspectos positivos sobre o país, conforme verificados nos enunciados do excerto 5:

\section{Excerto 5}

L 1- Nara: (...) What do you do on weekends in your city for having fun? Here in Brazil we usually go to the mall, go to the club and bowling.

L3 - Karen: i go clubbing and i like to dance.

(...)

L 4- N: Brazil is known by its hospitable people, carnival and soccer. We love soccer! Do you like soccer?

L6 - Jessica: World cup is big every where in the world but not in the USA since we have basketball, baseball, American football plus ice hockey. I'm more into baseball; as u know America has many major sports.

(...)

L9- $N$ : So you need to visit Brazil. It's very beautiful, many rivers and waterfalls. The people are happy and hospitable.

(...)

L $11-N:(\ldots)$ we have some famous artists here: Gisele Bundchen (top model), Rodrigo Santoro (actor). Do you know?

L $13-N:(\ldots)$ all food is perfect! Here, we eat rice and beans every day in all regions. What kind of food do you eat in your country?

L15 - J: Hello: Oh! I eat varies types if good. Here in southwest quite different then what I mainly eat.

A análise das declarações desta participante indicou que, no seu discurso, o global não se sobressaiu frente à sua identidade nacional, mas produziu novas e positivas identificaçóes com o local (HALL, 2006), como por exemplo, a valorização da natureza, tradições e atividades cotidianas típicas da nação brasileira. A lógica utilizada por Nara, embora bem-intencionada, seguiu os modelos globalizantes de homogeneização (assim como aconteceu com Bruna), já que as características do local foram apresentadas como uniformes e aplicáveis a todas as regiōes do território nacional e todos os brasileiros (linhas 
1, 2, 4, 5, 9, 10 e 13, do excerto 5). Nessa perspectiva, o discurso de Nara seguiu os discursos pautados pela ideologia do Estado-Nação, da qual fazem parte as noções imaginárias de um território nacional constituído por práticas e recursos homogêneos, sobretudo uma língua nacional homogênea e autossuficiente.

Ademais, movimentos transculturais puderam ser identificados na estratégia de construção identitária desta participante, nas vezes em que ela reuniu as informaçôes do local sob uma ordenação positiva e compreensível ao interlocutor aprendida no consumo dos discursos uniformizadores que trazem informações do exterior para o Brasil. Por exemplo, a exuberância de um país de natureza preservada registrada nas linhas 17, 19 e 22 do excerto 6 foi usada para realçar a preservação da natureza do Brasil, uma característica do país, prestigiada globalmente:

\section{Excerto 6}

L 17 - N: Brazil has beautiful beaches, rivers and waterfalls. (...)

(...)

L 18 - N: I live in [nome do estado]. Part of the Amazon forest is located in the state of $X$.

(...)

L 19- N: (...) There are many rivers with a variety of fish like Tambacú, Pintado, Dourado, Pirarucu, etc.

$L 21-N$ : The tourism is very important too. On vacation, many people visit the Brazil, because here have beautiful beaches, rivers and waterfall.

L 23 - J: You seem to live a very interesting place. Send photos if $\mathrm{u}$ wish.

O adjetivo beautiful (bonito) foi recorrente na descrição do Brasil e foi salientado por imagens retiradas da internet que Nara postou nas mensagens enviadas aos estrangeiros com os quais interagiu.

De modo similar, as ações cotidianas dos brasileiros foram escolhidas com base no padrão internacional (estratégia ii), conforme mostra a linha 24, do excerto 7 a seguir. Esta declaração foi enviada a todos os estrangeiros, na mensagem inicial de solicitação de amizade feita por Nara. Nesse caso, a associação do sujeito we com as açóes go the mall, the club and bowling (ir ao shopping, ao clube e jogar boliche) sugere que essas atividades são comuns no Brasil e realizadas por todos os brasileiros. A comparação com a descrição das atividades de fim de semana relatadas por dois estrangeiros que responderam 
a uma solicitação e a uma mensagem privada mostrou que estes escolheram usar o pronome I como Sujeito ao invés do we. Essa escolha parece ter dado um tom mais singular às ações mencionadas em comparação com a construção de Nara, conforme mostram as linhas 25 e 26:

\section{Excerto 7}

L 24 - Nara: We go to the mall, the club and bowling.

(...)

L 25 - Estrangeiro 1: I go clubbing and I like to dance.

(...)

L 26 - Estrangeiro 2: (...) 54 so I have grown out of the clubs and the bar scene.

Generalizações e homogeneizações similares a da linha 24 foram uma constante nos dados de Nara, que usou a imagem construída pelo EstadoNação para construir sua identidade para os interlocutores estrangeiros, não acrescentando dados, neste caso, que expressassem particularidades de sua identidade. A não ser pelo enunciado $M y$ English is not good ('Meu inglês não ébom'), não foram encontrados indícios de polaridade negativa nem tampouco de modalização. Assim, os dados de Nara indicam uma construção pautada em enunciados positivos e diretos.

\section{Considerações Finais}

Pode-se dizer que Bruna encontrou, na comunicação transnacional online, um espaço de reflexão e troca relativamente protegida dos olhares e julgamentos dos membros de seu grupo social mais imediato. O discurso ideológico do Estado-Nação a acompanhou nessa experiência e pode ser notado em alguns de seus contra-argumentos sobre o Brasil usados para construir sua identidade por meio de críticas ao sistema. A mediação tecnológica, neste caso, serviu para ela se conectar com outras pessoas que não encontrou no espaço físico onde estava.

No caso de Nara, sua identidade nacional sobressaiu na comunicação transnacional e foi supervalorizada. Na forma assíncrona, o tempo dedicado à elaboração da mensagem contribuiu ainda mais para a construção positiva da aparência. A distância entre os interlocutores e o desconhecimento da cultura um do outro influenciaram nessa construção. Por outro lado, características consideradas negativas e que poderiam ser denunciadas na interação, como, por exemplo, a falta do conhecimento perfeito da língua-alvo, foram declaradas para os amigos estrangeiros, com expressões do tipo My English is not good. 
A contraposição da análise dos dados de Bruna e Nara mostrou duas diferenças importantes: a primeira é que Bruna deixa implícito que o Brasil é um país ruim e os EUA é um país bom, e que ela está no lugar ruim, mas seu lugar verdadeiro é no lugar bom. Nara, por sua vez, acha que tudo o que ela é, o Brasil também é, e vice-versa. Tanto ela quanto o Brasil, nesse caso, são somente coisas boas. A diferença que fica marcada no discurso dessas duas brasileiras é que Nara não coloca o Brasil como se fosse inferior a outros países. Essa estratégia está em consonância com a identidade que ela constrói. Mesmo que o seu discurso não represente a sua prática, Nara reproduz o discurso do Estado-Nação usando, portanto, uma estratégia de discurso autorizada por instâncias maiores.

Outra diferença a esse respeito e que pode ter influenciado o discurso dessas duas brasileiras é que Bruna já esteve nos EUA ao passo que Nara não esteve nos países dos participantes com quem interagiu. A partir daí pode-se inferir que, embora a CMC possa prover contexto para uma prática autêntica e situada, viver essa autenticidade e contextualidade será tão mais possível e proveitoso quanto mais a pessoa já tiver acesso a outros contextos autênticos e situados de uso da língua, pelos caminhos normais.

Todavia, esta prática autêntica e situada envolve um planejamento que vai além do acesso à tecnologia ou a viagens, pois o senso comum diria que quem conhece um país pela mídia e pelas redes sociais poderia apenas tender a idealizar e supervalorizar o estrangeiro e desvalorizar o local, incorporando, inclusive, o discurso do outro, superior, sobre o local, inferior. Mas, mesmo assim, Bruna, que já viajou e conheceu as pessoas pessoalmente, continuou a desvalorizar o local e valorizar o estrangeiro. Contudo, Nara que não esteve nos países dos estrangeiros, não se comportou assim. Dois pontos importantes a esse respeito: o primeiro é que Bruna passou dez dias no exterior, teve um contato rápido com os amigos estrangeiros e, provavelmente, sentiu-se no outro país na situação de turista. Neste caso, é possível dizer que mesmo tendo viajado fisicamente, ela não saiu muito do virtual. Na posição de brasileira e analista do discurso de uma brasileira, sugiro que Nara, por outro lado, teve a mesma reação de Bruna, só que em relação aos estados do sul e sudeste, ou seja, a idealização hiperpositiva desses lugares, que ela também não conhece pessoalmente.

Assim, essas ponderaçōes nos leva a pensar sobre questôes sociais que não dependem dos avanços tecnológicos. Ou seja, de que adianta ter a possibilidade de se colocar estudantes em um contexto de prática autêntico caso a formação dele tenha sido toda feita em cima de situações de senso comum e estereótipos? 
Por um lado, o usuário fica perdido e acaba recorrendo ao estereótipo de si e do outro para se colocar. Por outro, a autenticidade de uma interação transnacional, por exemplo, não surte o efeito de envolvimento/motivação que se espera, porque a pessoa, de certa forma, já desenvolveu uma atitude diferenciada em relação ao uso da língua, como foi o caso de Nara. Certamente que isso depende do nível de proficiência da língua-alvo, mas também do envolvimento e de usos situados e autênticos para se chegar aos níveis mais altos de proficiência e envolvimento com a cultura-alvo.

A partir dessas considerações, os resultados sugerem que a questão central do tipo de iniciativa educacional na formação de cidadãos, aventada neste estudo, não é a superação desta ou daquela narrativa (seja a nação, ou qualquer outra), mas o pensar em uma globalização contra-hegemônica, não unilateral, ou melhor, na articulação dessa iniciativa de educação em línguas, com enfoque na formação do professor e do cidadão.

\section{Referências}

BAKHTIN, M. M. Speech genres and other later essays. Austin: The University of Texas Press, 1986. 177p.

BAUER, M. Classical content analysis: a review. In: BAUER, M.; GASKELL, G. (Ed.) Qualitative researching with text, image and sound. Thousand Oaks, CA: Sage, 2000. p. 131-151.

BAUMAN, Z. Identidade: entrevista a Benedetto Vecchi. Tradução Carlos Alberto Medeiros. Rio de Janeiro: J. Zahar, 2005. 112p.

BAYM, N.K. Interpersonal life online. In: LIEVROUW, L; LIVINGSTONE, S. (Ed.). Handbook of new media: social shaping and social consequences of ICTs. London: Sage, 1996. p.35-54.

BRASIL. Ministério da Educação. Secretaria de Educação Básica. Orientações curriculares para o ensino médio. Linguagens, Códigos e Suas Tecnologias: Conhecimento de Línguas Estrangeiras, Brasília, DF, 2006. Disponível em: <http:// portal.mec.gov.br/seb/arquivos/pdf/book_volume_01_internet.pdf $>$. Acesso em: 18 Jul. 2010.

BUZATO, M. E. K. Letramento e inclusão: do estado-nação à era das TIC. Revista D.E.L.T.A., v. 25, no 1, p. 01-38, 2009. Disponível em: <http://dx.doi. org/10.1590/S0102-44502009000100001>. Acesso em: 07 jul. 2010.

CILLIA, R.; REISIGL, M.; WODAK, R. The discursive construction of national identities. Discourse \& Society, London, v.10, nº.2, p.149-173, 1999. 
COIRO, J.; KNOBEL, M.; LANKSHEAR, C.; LEU, D. J. Central issues in new literacies and new literacies research. In: COIRO, J.; KNOBEL, M.; LANKSHEAR, C.; LEU, D. J. (Ed.). Handbook of research in new literacies. Mahwah, NJ: Lawrence Erlbaum Associates, Inc., 2008. p. 01-22.

COUTINHO, C. P.; CHAVES, J. H. O estudo de caso na investigação em tecnologia educativa em Portugal. Revista Portuguesa de Educação, v.1, no.15, p.221-43, 2002.

Disponível em: . Acesso em: 03 dez. 2012.

COX, M. I. P.; ASSIS PETERSON, A. A. Critical pedagogy in ELT: images of Brazilian teachers of English. TESOL Quarterly, v.33, no.3, p.433-452, 1999.

CUCHE, D. A noção de cultura nas ciências sociais. $2^{\mathrm{a}}$.ed. Tradução Viviane Ribeiro. Bauru: Edusc, 2002. 220p.

DERVIN, F. Cultural identity, representation and othering. In: JACKSON, J. (Ed.). The Routledge handbook of language and intercultural communication. London \& NY: Routledge, 2011.p. 181-194.

FAIRCLOUGH, N. Discourse and social change. Cambridge: Polity Press, 1992. 272p.

FAIRCLOUGH, N. Critical discourse analysis and the marketisation of public discourse: the universities. Discourse \& Society, London, v. 4, nº 2, p. 133-168, 1993. FAIRCLOUGH, N. Critical discourse analysis: the critical study of language. Boston: Addison Wesley, 1995.343p.

FAIRCLOUGH, N. Language and power. $2^{\text {nd }}$. ed. London: Longman. 2001. 226p. FAIRCLOUGH, N. Analysing discourse: textual analysis for social research. London: Routledge, 2003. 288p.

FAIRCLOUGH, N. Language and globalization. New York: Routledge, 2006. 200p.

FIORIN, J. L. Introdução ao pensamento de Bakhtin. São Paulo: Editora Ática, 2006. 144p.

FOUCAULT, M. The archeology of knowledge. London: Tavistock Publications, 1972. 218p.

FOWLER, R.; HODGE, R.; KRESS, G.; TREW, T. Language and control. London: Routledge \& Kegan Paul, 1979. 229p.

GARCÍA CANCLINI, N. Diferentes, desiguais e desconectados: mapas da interculturalidade. Tradução Luiz Sérgio Henriques. Rio de Janeiro: Editora da UFRJ, 2005. 283p. 
GIDDENS, A. As consequências da modernidade. Tradução Raul Fiker. São Paulo: Ed. Unesp, 1991. 180p.

HALL, S. A identidade cultural na pós-modernidade. Tradução Tomáz Tadeu da Silva; Guacira Lopes Louro. 11a. ed. Rio de Janeiro: DP\&A, 2006. 102p.

HALLIDAY, M. A. K. An introduction to functional grammar. London: Arnold, 1985.

HALLIDAY, M. A. K. An introduction to functional grammar. $2^{\text {nd }}$ ed. London: Arnold, 1994.

HALLIDAY, M. A. K.; MATTHIESSEN, C. Construing experience through meaning: a language-based approach to cognition. New York: Continuum, 1999. HALLIDAY, M. A. K.; MATTHIESSEN, C. An introduction to functional grammar. $3^{\text {rd }}$ ed. London: Hodder Arnold, 2004.

HERRING, S. C. International coherence in CMC. Journal of Computer Mediated Communication, v. 4, no 4, 1999. Disponível em: . Acesso em: 21 jan. 2011.

HERRING, S. C. Computer-mediated discourse. In: SCHIFFRIN, D.; TANNEN, D.; HAMILTON, H. (Ed.). The handbook of discourse analysis. Oxford: Blackwell Publishers, 2001. p. 612-634.

HERRING, S. C. Computer-mediated discourse analysis: an approach to researching online behavior. In: BARAB, S.A.; KLING R.; GRAY, J.H. (Ed.). Designing virtual communities in the service of learning. New York: Cambridge University Press, 2004a. p. 338-376.

HERRING, S. C. Online communication: through the lens of discourse. In: CONSALVO, M.; BAYM, N., HUNSINGER, J.; JENSEN, K. B.; LOGIE, J.; MURERO, M; SHADE, L. R. (Ed.). Internet Research Annual, volume 1. New York: Peter Lang, 2004b. p. 65-76.

KUMARADIVELU, B. Dangerous liaison: globalization, empire and TESOL. In: EDGE, J. (Ed.). (Re-)locating TESOL in an age of empire. London: Palgrave/ Macmillan, 2006. p. 1-26.

LUKE, C. Cyber-schooling and technological change: multiliteracies for the new times. In: COPE, B.; KALANTZIS, M. (Ed.). Multiliteracies: literacy learning and the design of social futures. New York: Routledge, 2000. p. 69-91.

MARKHAM, A. M. The internet as research context research. In: SEALE, C.; GOBO, G.; GUBRIUM, J.; SILVERMAN, D. (Ed.). Qualitative research practice. London: Sage, 2004. p.358-374.

MEURER, J. L. Gêneros textuais na análise crítica do discurso. In: MEURER, J. L.; BONINI, A. MOTTA-ROTH, D. (Org.). Gêneros: teorias, métodos, debates. São Paulo: Parábola, 2005. p. 81-106. 
MOITA LOPES, L. P. Identidades fragmentadas: a construção discursiva de raça, gênero e sexualidade em sala de aula. Campinas: Mercado das Letras, 2002.

ROGERS, E.M.; HART, W.B. The histories of intercultural, international and development communication. In: GUDYKUNST, W.B.; MODY, B. (Ed.). Handbook of international and intercultural communication. 2nd ed. Thousand Oaks: Sage, 2002. p.1-18.

ROJO, R. Gêneros do discurso e gêneros textuais: questóes teóricas e aplicadas. In: MEURER, J. L.; BONINI, A. MOTTA-ROTH, D. (Org.). Gêneros: teorias, métodos, debates. São Paulo: Parábola, 2005. p.184-207.

SANTOS, M. Por uma outra globalização: do pensamento único à consciência universal. Rio de Janeiro: Record, 2010.

WODAK, R. Disorders of discourse. London: Longman, 1996.

Data de submissão: 10/07/2013. Data de aprovação: 13/12/2013. 
